\title{
RISCOS E DESASTRES NATURAIS EM AMBIENTE URBANO: O EXEMPLO DE CUIABÁ/MT
}

\author{
ZAMPARONI, Cleusa A. Gonçalves Pereira - cazamp@gmail.com \\ Departamento de Geografia e PPG/GEO/UFMT - Univ. Federal de Mato Grosso
}

\begin{abstract}
RESUMO. Os desastres naturais são derivados da relação conflituosa sociedade/natureza e podem agravar as mudanças climáticas na escala local. Entretanto, os desastres naturais sempre fizeram parte da história da humanidade, inseridos no âmbito das (in)certezas e calcados na técnica e ciência na busca do controle sobre os eventos e domínio da natureza e resulta da combinação entre as características físicas do lugar, que refletem suas suscetibilidades e fragilidades associadas à capacidade de resposta e recuperação da sociedade expressas por sua vulnerabilidade e resiliência. A Revolução Industrial trouxe necessidades de reestruturações espaciais locais expressas pela urbanização crescente em nível mundial que estão atingindo elevados patamares no século XXI, gerando os desastres naturais nas áreas consideradas de risco. Em Cuiabá, a ocupação desordenada e a deficiência das políticas públicas de preservação da rede hídrica, de investimentos em saneamento e coleta de lixo provocam aumento significativo de inundações em bairros situados em áreas de risco. Estudos sobre o problema são necessários e urgentes, pois auxiliam a proposição e execução de ações preventivas em detrimentos das curativas, como as medidas para retirar e realocar, em definitivo, as pessoas que vivem em ocupações irregulares e de risco, pois em geral elas aceitam esta mudança enquanto estão em perigo e voltam quando cessa a turbulência. Assim sendo, o presente estudo objetiva analisar os riscos a desastres naturais urbanos em Cuiabá/MT com dados secundários fornecidos pela Defesa Civil local.

Palavras-chave: desastres naturais, área de risco, urbanização; inundações.
\end{abstract}

RISKS AND NATURAL DISASTERS IN URBAN ENVIRONMENT: THE EXAMPLE OF CUIABÁ / MT

ABSTRACT. Natural disasters are derived from the conflicting relationship among society and nature that may be aggravated by climate change. However, natural disasters have always been part of human history, within the scope of the (un)certainties and trampled in the pursuit of art and science in the pursuit of control over events and mastery of nature. Natural disaster results from the combination of the physical characteristics of place that reflects their sensibilities and frailties associated with response and recovery of society expressed by their vulnerability and resilience. The Industrial Revolution brought urban spatial restructuring needs expressed by the increasing urbanization worldwide that has reached high levels, in the century XIX, combined with the impacts of natural disasters at risk areas at risk areas. In Cuiabá (Mato Grosso, Brazil) disorderly occupation and disability policies for the preservation of public water network, investment in sanitation and garbage collection causes a significant increase in flooding in neighborhoods located in the flood area of the Cuiabá River. Studies on the problem are urgently needed, because they help to propose and implement preventive actions to the detriment of curative measures to move people living in illegal occupations in local problems involving risks to relocate this population, beyond the work of awareness, because in general people accept this change as they are in danger and come back when the turbulence ceases. Thus being, the present objective study to analyze the risks the urban natural disasters in Cuiabá/MT with secondary data supplied by the local Civil Defense.

Key-words: natural disasters, hazardous area, urbanization, flooding.

\section{INTRODUÇÃO}

Os desastres naturais sempre fizeram parte da história da humanidade, inseridos no âmbito das (in)certezas e calcados na técnica e ciência na busca do controle sobre os eventos e domínio da natureza. O desastre natural resulta da combinação entre as características físicas do lugar, que refletem suas suscetibilidades e fragilidades associadas à capacidade de resposta e recuperação da sociedade expressas por sua vulnerabilidade e resiliência.

A Revolução Industrial trouxe necessidades de reestruturações espaciais locais expressas pela urbanização crescente em nível mundial que estão atingindo elevados patamares no século XXI, gerando os desastres naturais nas áreas consideradas de risco.

A história da relação entre os homens e destes com os modos de apropriação e uso dos recursos naturais mostra vínculos com os desastres naturais com relevantes impactos na sociedade. Assim, os desastres naturais são derivados da relação conflituosa entre sociedade/natureza e que podem agravar as mudanças climáticas na escala local.

A inserção dos desastres naturais no âmbito das (in)certezas que permeiam as mudanças climáticas tem sido uma constante em vários estudos sobre a temática.

A produção e a reprodução do espaço geográfico mostram a intrincada e conflituosa relação entre os interesses políticos/econômicos de uma sociedade e as suas formas de apropriação da natureza. Neste contexto, os espaços e arranjos naturais são sobrepostos pelos espaços construídos pelas ações/aspirações antrópicas representado pela segunda natureza (SANTOS, 1994). Assim sendo, interferem nas interações e dinâmicas estabelecidas anteriormente provocando problemas socioambientais nas várias escalas de abordagem e análise. 
No âmbito do mundo globalizado e apoiado em uma política neoliberal a compreensão dos fenômenos socioeconômicos/ambientais, na escala local, deve ser realizada no contexto da escala global passando pela escala regional.

Assim, para trabalharmos com o conceito de escalas focada nas relações/interações entre os feitos da sociedade e os feitos da natureza (MONTEIRO, 1991) é necessário divorciá-lo do enfoque matemático. A escala cartográfica expressa a proporção que existe entre o mundo real e sua representação no papel em detrimento da enorme complexidade do termo quando se trata do recorte da realidade espacial.

A escala geográfica mostra a produção e (re)produção espacial, derivada dos aspectos sócio/econômicos/ambientais do extrato da realidade estudada e as suas interações e relações. Assim, a escala geográfica supõe a percepção do espaço total e do "fragmento" escolhido "compreender a diversidade e o choque entre intencionalidades em diversos níveis, as quais se revelam através de decisões e têm repercussão na ordem econômica, cultural, política e moral, assim como na ordem territorial" (SANTOS, 1988, p. 82).

Sob esse prisma, o fenômeno dos desastres naturais pode ser inserido no âmbito dos estudos das mudanças climáticas que afetam a sociedade moderna causando severos danos socioambientais, onde a vulnerabilidade está relacionada aos aspectos humanos e econômicos e a susceptibilidade ao estrutural ou físico.

O mundo moderno expresso pelo tripé composto pelas modalidades técnico/científico/informacional (SANTOS, 1984), inserido nas políticas neoliberais e um relevante processo de urbanização em escala global descortina os benefícios/malefícios da vida na cidade onde não só as áreas periféricas sofrem com a falta de infraestrutura e serviços. Neste contexto, a cidade tornou-se palco das diferenças/exclusões sociais em meio ao discurso da inclusão/benefícios de se habitar a área urbana.

Os efeitos maléficos derivados dos desastres naturais que historicamente tem atingido a população mais pobre, na atualidade, têm sido socializados com áreas habitadas pela população mais abastada economicamente. Entretanto, mesmo frente à intensidade e duração de um mesmo episódio, a população mais pobre apresenta um poder de resposta menos eficiente às perdas e o sofrimento vivenciado.

O espraiamento dos episódios de desastres naturais é uma realidade evidente mostrada pelos canais de comunicação e parece estar associado à crescente imobilidade do gestor público, nos diversos níveis, para lidar com a vulnerabilidade da população. Os variados graus de transtornos que os fenômenos naturais causam resultam da lógica social ordenadora do espaço onde ocorrem os embates de interesses, demandas e direitos dos grupos sociais. (VALENCIO et al. , 2009).

Assim sendo, torna-se necessário uma reflexão de como a configuração espacial no meio urbano, que é uma manifestação de processos socioeconômicos/ambientais e históricos específicos, está intimamente ligada à ocorrência de desastres naturais em áreas de risco.

O presente estudo objetiva analisar os riscos a desastres naturais urbanos em Cuiabá/MT com dados secundários fornecidos pela Defesa Civil local.

\section{A CIDADE E OS DESASTRES NATURAIS}

Partindo do pressuposto de que as transformações cristalizadas na escala local estão vinculadas às escalas regional, nacional e global e que o fenômeno local só pode ser compreendido a partir da conexão com a análise das influências políticas, socioambientais e econômicas vigentes (MONTEIRO e MENDONÇA, 2003), é possível afirmar que os desastres naturais estão associados, também, à forma como se processa a relação entre os homens, e destes com o modo de apropriação e uso dos recursos naturais.

O desastre natural é derivado da combinação entre as características físicas do lugar, que refletem suas suscetibilidades, fragilidades e a capacidade de resposta e recuperação da sociedade, expressas por sua vulnerabilidade e resiliência. 
A ordem de ocupação socioespacial nas cidades mostra que as áreas consideradas seguras do ponto de vista do risco a desastres naturais são valorizadas economicamente e incluídas na lógica da especulação imobiliária urbana dependendo de sua localização geográfica. Assim sendo, o desastre natural expressa a materialização da vulnerabilidade da população local. Conforme Santos (1994) a cidade é derivada das ações humanas no decorrer do processo histórico, sendo um produto social onde as aspirações individuais e/ou coletivas estão susceptíveis às decisões político/econômicas.

O risco é um fato capaz de modificar o território em sua dinâmica e funcionalidade por um período mais ou menos longo e com uma abrangência espacial mais ou menos difusa. Desastre, por sua vez, expressa a materialização do risco, e reflete a conjugação entre os fenômenos físicos e seus impactos nos grupos sociais, causando interrupção temporária ou permanente na rotina de funcionamento das atividades de um local. Os eventos físicos indutores podem ser de origem hidrológica (inundações fluviais e bruscas, deslizamentos), climatológica (ondas de frio e de calor, incêndios, seca), meteorológicas (tempestades tropicais severas, tornados) e geofísicas (tsunamis, erupções vulcânicas) (NUNES, 2009).

As causas do aumento na frequência e na intensidade dos desastres naturais podem ser múltiplas, estando entre elas o crescimento populacional e a ocupação de áreas de risco. Longe de refletir um processo cíclico e determinístico, elas espelham processos evolutivos a partir da interconectividade de variáveis dinâmicas, com um padrão de organização efêmero. Tais padrões podem evoluir a partir de incontáveis possibilidades que se colocam em um sistema cuja complexidade pode ser com a intensificação de extremos climáticos, como secas, vendavais, tempestades severas, inundações e ciclones, conforme atestam estudos diversos (IPCC, 2004 e 2007).

No âmbito das mudanças climáticas o monitoramento de desastres naturais é de fundamental importância para o planejamento de ações preventivas e para a definição de políticas públicas (IPCC 2004 e 2007). Para Nunes (2002), qualquer medida com vistas a limitar os impactos climáticos na sociedade deve considerar que o ambiente atmosférico é altamente dinâmico e, assim como os demais sistemas do planeta, está em franca transformação; dessa maneira, qualquer esforço nessa direção deve considerar o contexto das mudanças climáticas globais.

Ainda que crescendo em ritmo menos acelerado do que há algumas décadas, o aumento populacional é considerável, especialmente em alguns países nos quais as taxas de natalidade não têm sido substancialmente alteradas. Boa parte da expansão da população em áreas urbanas acontece em áreas de risco, o que evidencia que a oportunidade de uma vida com qualidade não se apresenta da mesma forma para todos. Isso faz com que parte da população, especialmente dos setores menos favorecidos economicamente, ocupem locais impróprios para moradia, por oferecerem riscos à vida, especialmente nas encostas e margens de rios (MATTEDI e BUTZKE, 2001; NUNES, 2009, entre outros). Dessa forma, as consequências de episódios calamitosos são sentidas de forma desigual pelos afetados, de acordo com a situação socioeconômica, a capacidade de resposta local e outros parâmetros que devem ser avaliados em prol da minimização das consequências deletérias dessas ocorrências (CASTELLANO e NUNES, 2007). Tal fato assinala que o aprofundamento do conhecimento científico sobre as causas dos efeitos desiguais dos desastres sobre a população torna-se cada vez mais imprescindível.

Segundo o relatório do UNDP - United Nations Development Program (2004), 75\% da população mundial vivem em áreas que foram afetadas pelo menos uma vez por ciclones, enchentes, secas e terremotos entre os anos de 1980 e 2000. Embora em alguns lugares os desastres naturais sejam mais frequentes que em outros, o convívio com eles não pode ser evitado e todos estão expostos a eles em diferentes graus (NUNES, 2009).

O IPCC - Painel Intergovernamental sobre as Mudanças do Clima (2001) - assinala que a população de alguns países é mais vulnerável aos efeitos negativos das mudanças climáticas. Assim, existe um claro padrão socioespacial de risco aos desastres naturais em nível mundial, 
pois as nações em desenvolvimento apresentam menor capacidade de resposta aos desastres e ocupação mais densa de áreas de risco. Como as mudanças climáticas estariam associadas a vários padrões de risco a desastres hidrometeorológicos, como maior incidência de chuvas fortes, esse fato se associa diretamente à segurança desses países.

Assim, são necessárias medidas de mitigação - um desafio global - combinadas com a adaptação, que deve ocorrer principalmente nos níveis locais e regionais. Logo, tanto mitigação como adaptação devem ser vistas como imperativo de segurança humana. Soma-se a isso, a necessidade de integrar o desenvolvimento de políticas e de planejamento para reduzir a pobreza. Dessa forma, aumenta-se a resiliência das populações, por meio de investimentos na proteção social, saúde, educação e outras medidas. Isso possibilita diminuir a vulnerabilidade em termos de oportunidades e na redução de um retrocesso do desenvolvimento humano das populações, principalmente as mais pobres.

Cada um desses mecanismos pode ser avaliado a partir da geração de inúmeros indicadores que passam a ser diferenciado quando são analisados em distintas unidades territoriais. Por conseguinte, isso possibilita aumentar o conhecimento sobre o grau de vulnerabilidade e resiliência das populações diante de eventos extremos e enriquece a diversidade de interpretações.

Uma das principais preocupações com as mudanças no clima é o aumento que poderá ocorrer nos episódios de eventos extremos. Estudo realizado com o apoio da ONU (2009) mostrou que as mudanças climáticas vão agravar desastres naturais, e que os moradores de países em desenvolvimento como Dominica, Vanuatu, Mianmar e Guatemala são os que correm maiores riscos. O estudo exortou os governos a investir centenas de bilhões de dólares para combater o impacto crescente de catástrofes como ciclones, enchentes, secas, deslizamentos de terra, terremotos e tsunamis, ainda que a capacidade de investimentos com vistas à prevenção seja extremamente desigual.

O secretário-geral da ONU, Ban Ki-moon, no relatório lançado durante as conversações climáticas da ONU realizadas em Bonn entre 1 e 12 de junho de 2009, no qual se trabalha sobre um novo tratado de combate ao aquecimento global, afirmou que "o risco é sentido mais agudamente por pessoas que vivem em favelas e em áreas rurais pobres". Para Andrew Maskrey, o autor principal do Relatório de Avaliação Global de Redução de Riscos de Desastres, "As mudanças climáticas vão ampliar a distribuição desigual do risco reforçando ainda mais os impactos de desastres sentidos pelas comunidades pobres dos países em desenvolvimento", pois os países em desenvolvimento liderados pela China, Índia, Bangladesh e Indonésia têm as populações maiores e são os que sofrem as grandes fatalidades em decorrência de desastres naturais.

Os desastres se colocam como grandes desestruturadores dos locais onde ocorrem, pelas perdas humanas, econômicas e materiais, sendo que a superação e recuperação dos seus impactos podem ser muito lentas e necessitam de auxílio externo. Em muitos casos eles representam um risco real e duradouro que impede o desenvolvimento econômico das sociedades envolvidas. Para exemplificar podemos citar o furacão Mitch, que em 1998 atingiu Honduras e outros países da América Central, provocando cerca de 11.000 óbitos, 2.500.000 desabrigados e um prejuízo estimado em US\$ 3,8 bilhões que comprometeu 0 desenvolvimento econômico do país de forma muito severa.

A calamidade é o ápice de um processo construído no cotidiano, especialmente em áreas que apresentam registros crônicos ou são negligenciadas. Ela ocorre quando a capacidade de resposta do indivíduo ou grupo chega no limite e espelham os conflitos da sociedade no trato com a natureza no que se refere à ocupação, produção e (re)produção do espaço geográfico.

Monteiro (1991) afirma que a existência do perigo é uma função do ajuste humano aos eventos naturais extremos; com isso, as enchentes não representariam perigo se as planícies inundáveis não fossem habitadas e, da mesma forma, os movimentos de massa não seriam perigosos se as encostas não fossem intensamente ocupadas. 
O quarto relatório do IPCC (2007) mostra que no tocante às mudanças climáticas as comunidades economicamente mais frágeis podem ser especialmente vulneráveis, em particular aquelas concentradas em áreas de alto risco. Elas costumam ter capacidades de adaptação mais limitadas e são mais dependentes dos recursos sensíveis ao clima, como a oferta local de água e alimento. Com a intensificação dos eventos climáticos extremos, os custos econômicos e sociais dessas ocorrências aumentarão e serão substanciais nas áreas afetadas mais diretamente.

Acima de tudo, enfrentar os danos causados pelos desastres naturais requer aumentar a compreensão da dinâmica dos eventos naturais e como eles se expressam em diferentes contextos socioespaciais, além de melhorar a capacidade para suas previsibilidades. É uma questão geográfica por excelência, por refletir as formas como o meio técnico-científico faz a intermediação entre sociedade e natureza em um mundo globalizado, no qual, nas palavras de Camargo (2005), a técnica hegemônica e o mesmo modelo de desenvolvimento estariam na base dos problemas entre as populações e o meio natural. Soluções, portanto, requerem uma ruptura nessa interpretação única, considerando as especificidades dos lugares.

Assim, faz-se necessário buscar perspectivas nas dimensões qualitativa e quantitativa dos estudos climáticos como fenômeno socioambiental, que no estágio atual do desenvolvimento da ciência e da sociedade é considerado um dos elementos do suporte físico do espaço geográfico, e que adquire relevância no sentido de que sua configuração pode facilitar ou dificultar a instalação do homem e de suas atividades nos mais diversos locais do planeta.

\section{Ocupação socioespacial de Cuiabá no contexto de Mato Grosso}

Mato Grosso possui localidades sujeitas a uma variedade de desastres naturais tais como tempestades severas, enxurradas, inundações, secas e estiagens, incêndios florestais e vendavais, que afetam centenas de pessoas, em especial, a partir da década de 1970 com o processo histórico da Marcha para o Oeste e o início da colonização pública e privada de sua porção norte e a BR 163.

A história da ocupação espacial de Mato Grosso foi pautada por vários insucessos até meados dos anos de 1960. Objetivando promover seu desenvolvimento socioeconômico e sua inserção no conjunto da economia nacional, a materialização das estratégias de ocupação da região concretizou-se com a transferência da capital federal para o Planalto Central nos anos 1960, fato que acarretou profundas modificações nesse espaço.

A ocupação do Mato Grosso pelas frentes pioneiras por meio do processo de colonização refletiu esses interesses. Contribuindo com o fortalecimento deste processo foram sendo criados os PNDS - Planos Nacionais de Desenvolvimento objetivando a promoção do desenvolvimento de todos os setores da economia nacional de forma integrada.

A produção do espaço urbano de Cuiabá/Mato Grosso deve ser compreendida no contexto da produção e (re)produção do espaço mato-grossense a partir da década de 1970, derivado do processo migração, via colonização oficial e privada. Como grande parte das cidades brasileiras, Cuiabá tem sido afetada por uma série de processos socioeconômicos impactantes no ambiente físico original. Dentre eles, merece destaque à ocupação das áreas de preservação permanente.

Cuiabá é a capital do Estado de Mato Grosso e está localizada entre as latitudes $15^{\circ} 37^{\prime}$ e $15^{\circ} 43^{\prime}$ Sul e longitudes de $56^{\circ} 03^{\prime}$ e $56^{\circ} 08^{\prime}$ Oeste de Greenwich, abrangendo uma área total de $254,57 \mathrm{Km}^{2}$ de perímetro urbano, no centro geodésico da América do Sul, (IPDU, 2007) (Figura 1). A área urbana é drenada pelo rio Cuiabá e seus afluentes, dos quais se destacam o Rio Coxipó e inúmeros córregos, tais como: Córrego da Prainha, Ribeirão da Ponte, Manoel Pinto, Moinho, Barbados, Gambá e São Gonçalo.

O núcleo urbano de Cuiabá foi criado em 1719 e recebeu foros de cidade em 1818. Sua origem está ligada ao ciclo do ouro, que trouxe a imigração inicial para a região. A população de Cuiabá era de 35.987 hab. em 1872, de 54.394 hab. em 1940 e de 56.828 hab. em 1960, o 
que mostra um baixo crescimento demográfico nesse período. Em 1970 a população era de 108.860 habitantes e em 1980 praticamente havia duplicado o número de hab., com 212.980 pessoas. Atualmente o número de habitantes é de 550.562 , com $95 \%$ da população residente na zona urbana (IBGE, 2010).

A cidade apresenta uma malha viária antiga, de traçado irregular, principalmente no centro da cidade, com ruas estreitas, características de uma ocupação em região de garimpo, alternadas com avenidas mais amplas que se multiplicaram após a década de 1970.
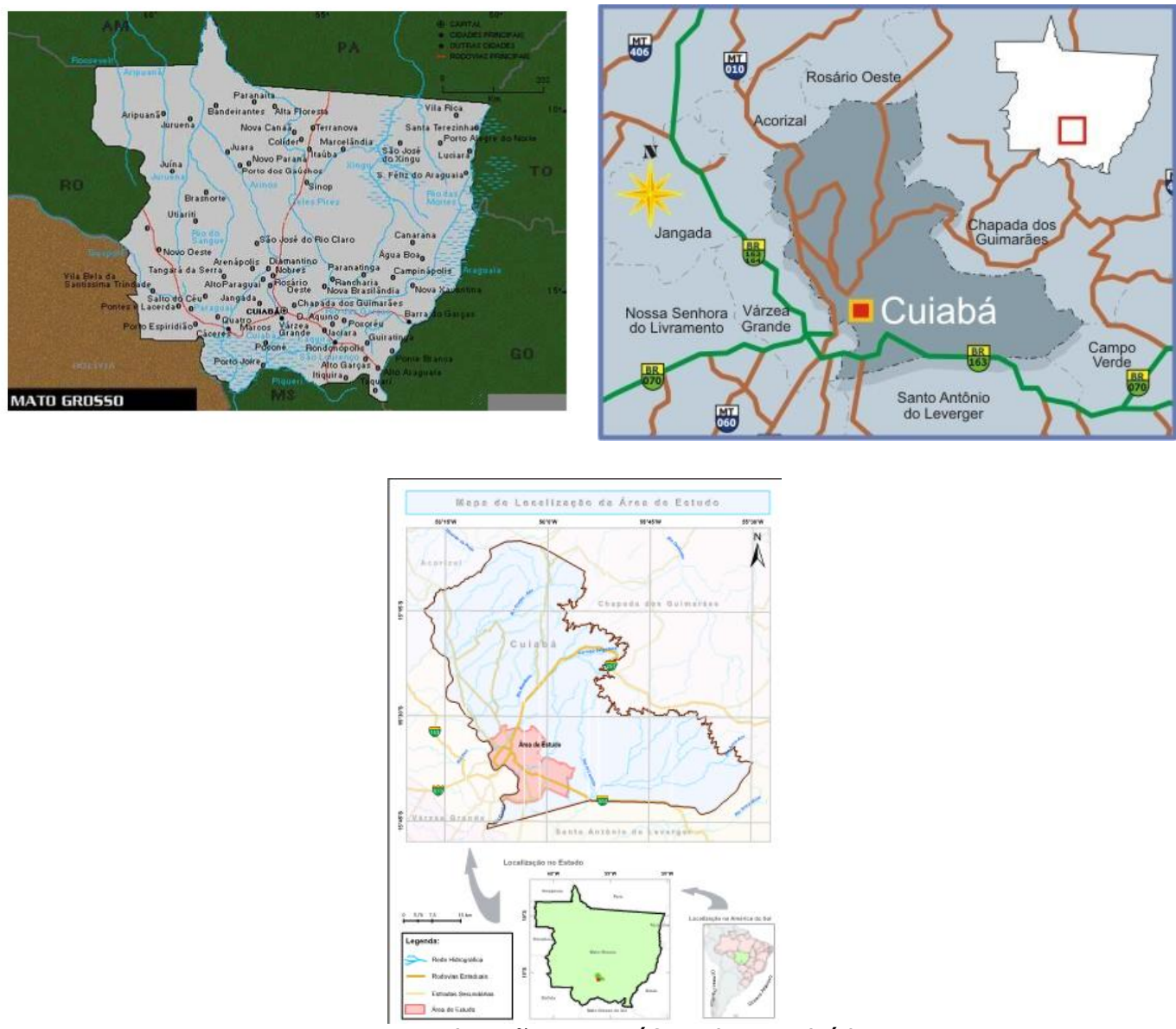

Figura 1. Localização geográfica de Cuiabá/MT.

Fonte: Mato Grosso e Seus Municípios 2007.

A maior parte das áreas de risco a enchentes localizam as margens do rio Cuiabá e adjacências. Esta ocupação é formada por grilos, invasões, propriedades sem documentação legalizada junto aos órgãos de planejamento do município. Grande parte da população de baixa renda vive nestas localidades.

\section{DESASTRES NATURAIS: INUNDAÇÕES EM CUIABÁ/MT}

Em Cuiabá, a ocupação desordenada e a ineficiência de políticas públicas de preservação da rede hídrica, de investimentos em saneamento e coleta de lixo provocam aumento significativo de episódios de inundações, principalmente, em bairros situados as margens do rio Cuiabá. Diferentemente das enchentes do rio, ocorridas em 1942, 1974, 1995 e 2001, em todo o planalto da Bacia do Rio Cuiabá, as inundações recentes estão mais relacionadas com erosões e entupimento das calhas dos 36 córregos que cortam a capital e deságuam nos rios Cuiabá e Coxipó.

Segundo dados da Defesa Civil de Cuiabá (2009) existem 5,5 mil famílias vivendo em áreas de risco nas margens dos córregos e rios, situadas numa área total de 136 hectares que, pelo Código Florestal Brasileiro, deveriam ter sido respeitadas por serem Áreas de Preservação Permanente (APPs). Para Araujo (2010) existem 36 córregos em Cuiabá/MT localizados em 
APP's e nestes locais, a mata ciliar foi quase que totalmente dizimada e, vários córregos foram aterrados. Foi constatado que dos $208.439 \mathrm{~km}$ de extensão dos córregos da cidade, 172.357 $\mathrm{km}$ estão contaminados por esgoto e lixo.

De acordo com dados da Secretaria Nacional de Defesa Civil (SEDEC, 2010), em Mato Grosso, nos meses de janeiro e fevereiro de 2010, 876 pessoas foram afetadas por desastres naturais como erosão, enxurradas ou inundações.

O Jornal A Gazeta (2009) mostrou que em Cuiabá/MT a ocupação urbana nos arredores dos 36 córregos que deságuam nos rio Cuiabá e Coxipó, vem agravando o problema das inundações e alagamentos na cidade. As enchentes ocorreram em Cuiabá nos anos de 1942, 1974 e 1995 se deram devido às cheias do rio Cuiabá que afetou toda região da Baixada Cuiabana e o Pantanal. Castro (2009) mostrou que não há vida em $80 \%$ dos córregos existentes em Cuiabá. Além das áreas localizadas no entorno do rio Cuiabá, na atualidade os 36 córregos que fazem parte de Cuiabá estão contaminados com entulhos e lixos de toda a espécie contribuindo com entupimentos e servindo de barreira para o escoamento das águas pluviais. Nestes locais vive a população que tem sido mais atingida pelos episódios de enchentes, na estação chuvosa.

As informações acima se encontram relacionadas à suscetibilidade de Cuiabá no enfrentamento a episódios de enchentes que são recorrentes, pois as ações preventivas ficam em segundo plano em relação às curativas.

Os desastres naturais, em especial as enchentes e inundações que ocorrem em Cuiabá/MT podem ser relacionados às políticas públicas de produção e (re)produção do uso do solo urbano. Uma avaliação da legislação que incide sobre as áreas urbanas permitiu evidenciar a desarticulação e contradição entre políticas públicas voltadas à habitação e meio ambiente, acirrando as discussões entre os princípios fundamentados na Constituição Federal, quais sejam, o direito à moradia e o direito ao meio ambiente ecologicamente equilibrado.

Destaca-se, ainda, que as APP's são áreas que cumprem elevada importância ambiental, em especial, na manutenção da integridade e da qualidade das águas dos cursos d'água. Os órgãos de planejamento e execução das políticas públicas municipal necessitam de instrumentos de análise como os mapeamentos geotécnicos e de áreas de riscos contendo a situação de suscetibilidade física e vulnerabilidade da população para compor os instrumentos de intervenção e gestão do espaço urbano como o plano diretor.

As construções foram realizadas em áreas de preservação às margens dos córregos a mata ciliar foi quase que totalmente retirada. Aliado à esta situação vários córregos foram aterrados. Foi constatado que dos 208.439 km de extensão dos córregos da cidade, 172.357 km estão contaminados por esgoto e lixo.

Para Castro (2009), no caso de Cuiabá as consequências podem ter sido irreversíveis, pois algumas nascentes foram extintas como, por exemplo, a do Córrego Canjica, onde prédios na Avenida do CPA foram construídos sobre os olhos d'água.

Embora as enchentes causadas pelo rio Cuiabá possam ser consideradas naturais devido às condições físicas do local - como características geológicas, hidrogeológicas dos terrenos e declividade das vertentes -, por causa da ocupação urbana irregular, a população estará sempre em situação de risco e vulnerável às inundações.

É importante registrar que a população que é obrigada a se mudar do local de moradia por conta dos riscos de enchentes, na maioria das vezes, não ficam satisfeitas com a situação vivenciada e voltam à origem mesmo correndo perigo de enfrentamento de novos desastres naturais.

Assim, a situação pós-desastres naturais, normalmente, é traumática e traz muitos episódios de intranquilidade para a população envolvida, Defesa Civil e os órgãos de planejamento da cidade.

A tabela 1 mostra um resumo das ocorrências de enchentes em Cuiabá/MT, registrada no Perfil Socioeconômico do município de Cuiabá (2009). Os dados evidenciam que desde 1780 as enchentes fazem parte da estória de Cuiabá. Episódios de mesma magnitude podem ter 
causado danos diferentes devido ao processo histórico de ocupação, produção e (re)produção espacial em que ocorreram. Entretanto, algumas informações nos parecem relevante dado o caráter de recorrência. Trata-se dos episódios de 1942 e o ocorrido em 1974 que apresentaram valores das cotas de água do rio Cuiabá semelhantes em um espaço de 32 anos. No contexto da estória dos eventos das enchentes de Cuiabá a mais marcante foi a de 1974 quando a cidade já passava por transformações profundas tanto no aumento do seu número de habitantes como de sua posição estratégica para a ocupação do espaço norte matogrossense a partir do processo de colonização que começou em 1970.

Tabela 1

Resumo das ocorrências de enchentes em Cuiabá/MT

\begin{tabular}{|l|l|l|}
\hline Data & Descrição & $\begin{array}{l}\text { Intervalo entre as } \\
\text { Ocorrências }\end{array}$ \\
\hline 1780 & $\begin{array}{l}\text { Primeiro Registro de } \\
\text { Enchente em Cuiabá }\end{array}$ & - \\
\hline 1812 & Destruiu a 10 Chácara & 32 anos \\
\hline 1865 & $\begin{array}{l}\text { Danos em edificações no } \\
\text { 2o Distrito (atual bairro } \\
\text { Porto) }\end{array}$ & 53 anos \\
\hline 1895 & $\begin{array}{l}\text { Cheia de menor proporção } \\
\text { que a anterior }\end{array}$ & 30 anos \\
\hline 1905 & $\begin{array}{l}\text { Assustou moradores e as } \\
\text { casas foram abandonadas }\end{array}$ & 10 anos \\
\hline 1906 & $\begin{array}{l}\text { Enchente de janeiro, só } \\
\text { não excedeu a de } 1865\end{array}$ & 1 ano \\
\hline 1942 & $\begin{array}{l}\text { O rio atingiu 10,57 m } \\
\text { atingindo vários bairros }\end{array}$ & 36 anos \\
\hline 1960 & $\begin{array}{l}\text { Atingiu a Av. XV de } \\
\text { novembro }\end{array}$ & 18 anos \\
\hline 1974 & $\begin{array}{l}\text { Atingiu violentamente o } \\
\text { bairro do Terceiro, a cota } \\
\text { do rio atingiu 10,87 m }\end{array}$ & 14 anos \\
\hline 1995 & $\begin{array}{l}\text { Vários bairros foram } \\
\text { atingidos, a cota foi de } \\
10,38 \text { m }\end{array}$ & 21 anos \\
\hline
\end{tabular}

Fonte: Perfil Socioeconômico do município de Cuiabá (2009). IPDU - Instituto de Planejamento e Desenvolvimento Urbano (adaptado).

Shirashi (2003) elaborou um estudo detalhado sobre os últimos acontecimentos de enchentes no rio Cuiabá que atingiu a área urbana de Cuiabá/MT, causando prejuízos materiais. Mostrou que desde que foi instalada a régua para medir a cota d'água do rio Cuiabá, ocorreram 17 eventos que registram cotas da medida da água com, mas de 10 metros de magnitude. Assim, o histórico das enchentes já apontava problemas em 1942 com recorrências em 1959, 1960 e em 1974, cujos danos à população e materiais foram bastante significativos. Estas informações podem ser visualizadas na tabela 2 .

A régua linimétrica está localizada no Bairro Porto próximo à ponte Julio Muller desde 1933, e é a única localizada no perímetro urbano de Cuiabá. Segundo Shirashi (2003), o marco localizado na Praça do Porto também é o ponto de referência com 148 m na cota do IBGE. 
Tabela 2

Cotas das grandes cheias registradas em Cuiabá/MT

\begin{tabular}{|c|c|}
\hline ANO & COTA (M) \\
\hline 1935 & 9,18 \\
\hline $\mathbf{1 9 4 2}$ & $\mathbf{1 0 , 5 7}$ \\
\hline 1943 & 8,58 \\
\hline 1945 & 9,0 \\
\hline 1946 & 8,82 \\
\hline 1949 & 8,96 \\
\hline 1954 & 9,02 \\
\hline $\mathbf{1 9 5 9}$ & $\mathbf{1 0 , 1 0}$ \\
\hline $\mathbf{1 9 6 0}$ & $\mathbf{1 0 , 3 9}$ \\
\hline 1961 & 8,56 \\
\hline 1968 & 8,56 \\
\hline $\mathbf{1 9 7 4}$ & $\mathbf{1 0 , 8 7}$ \\
\hline 1979 & 9,18 \\
\hline 1980 & 9,0 \\
\hline 1982 & 8,88 \\
\hline 1988 & 8,61 \\
\hline $\mathbf{1 9 9 5}$ & $\mathbf{1 0 , 5 0}$ \\
\hline
\end{tabular}

Fonte: Shirashi, 2003.

As áreas de risco de acordo com o perfil socioeconômico dos bairros organizado pela Prefeitura Municipal de Cuiabá podem ser visualizados no Quadro 1.

Quadro 1

Localização das Áreas de Risco e Perfil Socioeconômico de Cuiabá/MT

\begin{tabular}{|c|c|c|}
\hline $\begin{array}{c}\text { Bairro e número de } \\
\text { habitantes }\end{array}$ & Localização & $\begin{array}{c}\text { Características } \\
\text { Socioeconômicas/salários } \\
\text { mínimos }\end{array}$ \\
\hline Praeirinho - 2.102 & $\begin{array}{l}\text { Região Leste em uma } \\
\text { área de } 41,14 \text { ha }\end{array}$ & $\begin{array}{l}\text { Renda baixa - média salarial } \\
\text { de } 2,72 \text { salários mínimos. }\end{array}$ \\
\hline Parque Atalaia - 3.445 & $\begin{array}{l}\text { Região Sul e possui uma } \\
\text { área de } 558,88 \text { ha }\end{array}$ & $\begin{array}{l}\text { Renda médio-baixa - média } \\
\text { salarial de } 4,16 \text { salários } \\
\text { mínimos. }\end{array}$ \\
\hline Parque Geórgia - 668 & $\begin{array}{l}\text { Região Sul em uma área } \\
\text { de } 325 \text { ha }\end{array}$ & $\begin{array}{l}\text { Renda médio-baixa }-3,35 \\
\text { salários mínimos. }\end{array}$ \\
\hline $\begin{array}{l}\text { Terceiro (São Mateus) - } \\
2.110\end{array}$ & Região Leste - 86,20 ha & $\begin{array}{l}\text { Baixa renda - média salarial } \\
\text { de } 2,71 \text { salários mínimos. }\end{array}$ \\
\hline Porto - 9.335 & Região Oeste - 248,22 ha & $\begin{array}{l}\text { Renda média }- \text { média } \\
\text { salarial é de } 7,38 \text { salários } \\
\text { mínimos. }\end{array}$ \\
\hline Coophamil - 6.005 & Região Oeste - 189,07 ha & $\begin{array}{l}\text { Renda média - média de } \\
8,58 \text { salários mínimos. }\end{array}$ \\
\hline Novo Terceiro - 3.774 & Região Oeste - 34.69 ha & $\begin{array}{l}\text { Renda média-baixa - média } \\
\text { salarial de } 2,71 \text { salários } \\
\text { mínimos. }\end{array}$ \\
\hline Cidade Verde - 2.757 & Região Oeste - 48,84 ha & $\begin{array}{l}\text { Renda médio-baixa - renda } \\
\text { média salarial de } 5,38 \\
\text { salários mínimos. }\end{array}$ \\
\hline $\begin{array}{l}\text { Jardim Santa Izabel - } \\
9.375\end{array}$ & Região Oeste - 139,52 ha & $\begin{array}{l}\text { Renda médio-baixa - média } \\
\text { salarial é de } 3,17 \text { salários } \\
\text { mínimos. }\end{array}$ \\
\hline Pari -6.265 & Região Oeste - 235,59 ha & Renda média $\quad-\quad 10,47$ \\
\hline
\end{tabular}




\begin{tabular}{|l|l|l|}
\hline Ribeirão da Ponte - 2.287 & Região Oeste - 37,56 ha & $\begin{array}{l}\text { salários mínimos. } \\
\text { Renda médio-baixa - média } \\
\text { de 5,2 salários mínimos. }\end{array}$ \\
\hline Ribeirão do Lipa - 2.244 & Região Oeste - 396,87 ha. & $\begin{array}{l}\text { Renda baixa - média de } \\
\text { renda de 2,86 salários } \\
\text { mínimos. }\end{array}$ \\
\hline Três Barras - 6.495 & Região Norte - 127,29 ha & $\begin{array}{l}\text { Renda baixa com média de } \\
2,41 \text { salários mínimos. }\end{array}$ \\
\hline Jardim dos Ipês - 2.042 & Região Sul - 45,33 há & $\begin{array}{l}\text { Renda médio-baixo, com } \\
\text { média salarial de 4,83 } \\
\text { salários mínimos. }\end{array}$ \\
\hline Bela Marina - 473 & Região Leste - 110,66 ha & $\begin{array}{l}\text { Renda médio-alta média } \\
\text { da renda é de 14,39 salários } \\
\text { mínimos }\end{array}$ \\
\hline $\begin{array}{l}\text { São Gonçalo Beira Rio - } \\
290\end{array}$ & Região Sul - 106,58 ha & $\begin{array}{l}\text { Renda média - média de } \\
\text { renda de 7,01 salários } \\
\text { mínimos }\end{array}$ \\
\hline
\end{tabular}

Fonte: Perfil Socioeconômico de Cuiabá, 2007 adaptado por Cleusa A. G. P. Zamparoni

Tucci e Marques (2000) destacam que a impermeabilização e a canalização aumentam em até sete vezes as vazões máximas das cidades urbanizadas.

Por isso, a Prefeitura de Cuiabá e o Ministério da Integração Regional, por meio da Secretaria de Desenvolvimento do Centro-Oeste, para resolver o problema de inundação no Bairro São Mateus, pretendem realizar obra de ampliação da travessia do córrego do Gambá na região da Avenida Beira-Rio, facilitando o escoamento das águas da chuva.

Cuiabá possui hoje 13,6 milhões de metros quadrados, ou 136 hectares, de locais de risco. A Defesa Civil local calcula que cerca de 5,5 mil famílias vivem nessas regiões. Os principais problemas se referem à ocupação de Áreas de Preservação Permanente (APP) nas margens dos 36 córregos e dois rios que banham a capital. Nestes locais ocorrem alagamento e enchentes nos períodos mais chuvosos do ano. Apenas em janeiro e fevereiro de 2010 a Secretaria Nacional de Defesa Civil (SEDEC) registrou em Mato Grosso 876 pessoas afetadas por erosão e enxurradas ou inundações bruscas.

As informações acima se encontram relacionadas à suscetibilidade de Cuiabá no enfrentamento a episódios de enchentes que são recorrentes, pois as ações preventivas ficam em segundo plano em relação às curativas.

Entretanto, com a construção da Usina de Manso, passou a existir certo controle sobre o volume das águas pluviométricas sobre o rio Cuiabá e foi possível evitar outra enchente no ano de 2010 que registrou o maior volume de chuva dos últimos 79 anos, chegando a atingir 423,6 $\mathrm{mm}$, quando a média histórica é de $220,0 \mathrm{~mm}$. O rio Cuiabá atingiu a cota de 8,0 metros na régua linimétrica, sendo que a cota de alerta é a partir de 8,5 metros. Não fosse o fechamento das comportas da usina, a cota chegaria a 9,5 metros. Isso foi devido à usina ter capacidade de $80 \%$ do seu volume, portanto, foi capaz de captar um maior volume de águas pluviais e manter o escoamento controlado através das comportas. (RODRIGUES, 2010).

Entre os anos de 1996 a 2010, não foram registradas enchentes de grande porte que assolavam grande parte da população ribeirinha do município de Cuiabá.

Para Mauro (2010), desde então, o risco de enchentes foi diminuído pelo controle de vazão de água realizado pela barragem da usina de Manso, a preocupação maior são os córregos localizados na área urbana de Cuiabá/MT, que devido ao grande volume de água das chuvas combinado com a impermeabilidade do solo urbano (asfalto e concreto) e presença de obstruções (lixo), tem a sua capacidade superada e pode causar alagamentos e afetar bairros localizados em suas margens.

Segundo Castro (2009), essas áreas deveriam estar protegidas por lei, pois a maioria está localizada em Áreas de Proteção Permanente (APP's), mas concorre com essa teoria um 
projeto de lei municipal que reduz mais ainda as APP's e as Zonas de Interesse Ambiental (ZIA), tudo por motivo do crescimento imobiliário da cidade. O Quadro 2 traz informações sobre os principais córregos e os bairros onde se localizam em Cuiabá.

Quadro 2

\section{Principais córregos de Cuiabá}

\begin{tabular}{|c|c|}
\hline Córregos & Bairros por onde passam \\
\hline Castelhano & Distrito Industrial. \\
\hline Moinho & $\begin{array}{l}\text { Novo Horizonte, } 1^{0} \text { de Julho, Jardim Itamarati, Recanto dos } \\
\text { Pássaros, Santa Cruz, Residencial JK e Chácara dos Pinheiros. }\end{array}$ \\
\hline Figueirinha & Nossa Senhora Aparecida, Jardim Mossoró, Parque Cuiabá \\
\hline Gambá & $\begin{array}{l}\text { São José dos Lázaros, Lixeira, Barro Duro, Areão, Jardim } \\
\text { Guanabara, Poção, Dom Aquino, Jardim Paulista, São Mateus e } \\
\text { Grande Terceiro. }\end{array}$ \\
\hline Ouro Fino & Ouro Fino, Vila Nova, João Bosco Pinheiro. \\
\hline Ribeirão do Lipa & Parque Mãe Bonifácia, Santa Rosa, Jardim Colorado. \\
\hline $\begin{array}{l}\text { Tancredo Neves } \\
\text { ou Gumitá }\end{array}$ & $\begin{array}{l}\text { Centro Político Administrativo, Centro América, Tancredo Neves, } \\
\text { Morada do Ouro, Novo Mato Grosso, Três lagoas, Novo } \\
\text { Horizonte, Planalto, Primeiro de Julho. }\end{array}$ \\
\hline Caité & Distrito Industrial. \\
\hline Pinheira & Residencial Sucuri. \\
\hline Engole Cobra & Pólvora, Porto, Cidade Alta. \\
\hline Fortaleza & Jardim Novo Milênio, Cohab Novo Milênio, Santa Laura. \\
\hline Lavrinha & Parque Cuiabá, Parque Atalaia, São Gonçalo Beira Rio. \\
\hline Prainha & $\begin{array}{l}\text { Senhor dos Passos, Araés, Lixeira, Baú, Centro Norte, } \\
\text { Bandeirantes, Centro Sul, Dom Aquino, Porto e Novo Terceiro. }\end{array}$ \\
\hline Santa Isabel & Santa Isabel e Verdão. \\
\hline Três Barras & $\begin{array}{l}\text { Aroeira, Morada da Serra, Vila da Serra, Nova Conquista, } 1^{\circ} \text { de } \\
\text { Março, Jardim Brasil, Três Barras, Três Lagoas, Novo Horizonte, } \\
\text { Altos da Serra, } 1^{\circ} \text { de Julho }\end{array}$ \\
\hline Baú & $\begin{array}{l}\text { Jardim Florianópolis, Jardim União, Jardim Vitória, Centro Político } \\
\text { Administrativo. }\end{array}$ \\
\hline Cajú & $\begin{array}{l}\text { Serra Dourada, Aroeira, Morada da Serra, Vila da Serra, Nova } \\
\text { Conquista, Residencial Ana Maria, João Bosco Pinheiro. }\end{array}$ \\
\hline Barbado & Parque Massairo Okamura, Morada do Ouro, avenida do CPA. \\
\hline Escuro & Parque Atalaia. \\
\hline Fundo & $\begin{array}{l}\text { Jardim Itália, Morada dos Nobres, Santa Cruz, Boa Esperança e } \\
\text { Residencial JK. }\end{array}$ \\
\hline Mané Pinto & $\begin{array}{l}\text { Bairro Popular, Jardim Cuiabá, Jardim Primavera, Goiabeiras, } \\
\text { Verdão, José Pinto, Cidade Alta e Porto. }\end{array}$ \\
\hline Quarta-feira & $\begin{array}{l}\text { Centro Político Administrativo, Monte Líbano, Antônio Dias, } \\
\text { Loteamento Eldorado, Santa Marta, Altos da Boa Vista. }\end{array}$ \\
\hline São Gonçalo & $\begin{array}{l}\text { Tijucal (lagoa azul), São Francisco, Vila Verde, Jardim Presidente } \\
\text { I, Cohab São Gonçalo, Nossa Senhora Aparecida, Parque } \\
\text { Geórgia, São Gonçalo. }\end{array}$ \\
\hline $\begin{array}{l}\text { Ribeirão } \\
\text { Peixes }\end{array}$ & Pedra 90. \\
\hline
\end{tabular}

Fonte: A Gazeta, 2009.

Dos 208.439 quilômetros de extensão dos córregos que cortam Cuiabá, 172.357 quilômetros de águas já estão contaminados por esgoto e lixo (GAZETA, 2009). Esse problema no período de chuva acaba gerando problemas de alagamentos e inundações em diversos bairros do município, particularmente aqueles, mencionados nos passos anteriores, que ficam localizados na área de risco.

Os desastres naturais, em especial as enchentes e inundações que ocorrem em Cuiabá/MT podem ser relacionados às políticas públicas que norteiam a produção e (re) produção do uso 
do solo urbano expressa pela desarticulação e contradição entre políticas públicas voltadas à habitação e as condições ambientais, acirrando as discussões entre os princípios fundamentados na Constituição Federal, como o direito à moradia e ao ambiente ecologicamente equilibrado.

Destaca-se, ainda, que as APP's cumprem elevada importância ambiental, em especial, na manutenção da integridade e da qualidade das águas dos cursos d'água. Trata-se de áreas cobertas ou não por vegetação. Contudo, uma vez alterada sua estrutura, dificilmente cumprirão sua função natural.

A informalidade, ou clandestinidade existente no ambiente urbano desafia a gestão pública da cidade, contudo impelem à necessidade cada vez maior de integração das diferentes políticas públicas, em especial, as relativas à natureza e sociedade.

Sob este aspecto, destaca-se a importância da gestão ambiental urbana. A regularização das situações clandestinas poderá permitir ao Poder Público exigir ou promover melhorias nas condições de habitação e, consequentemente, de qualidade das águas dos cursos d'águas investigado.

Segundo ARAUJO (2010), as Áreas de Preservação Permanente, constituem uns totais aproximados de $1.601,78$ hectares, sendo 617,40 hectares de Área de Preservação Permanente Degradada. A maior parte dessas áreas encontra-se alterada pela forma desordenada de ocupação, exigindo estratégia e ações que permitam reabilitar o equilibro hidrológico e harmonizado a paisagem. O autor sugere que a Prefeitura Municipal de Cuiabá implante ações voltadas à recuperação da área degradada, além da promoção de melhorias na infraestrutura, podendo ser submetido a agentes financiadores.

Assim sendo, torna-se necessário sensibilizar a sociedade da importância de se preservar as matas ciliares, divulgando as diretrizes legais que versam sobre a preservação das matas ciliares, e reprimir, num âmbito administrativo, tal prática predatória, impondo as sanções aos infratores, em especial multa e obrigando a restaurar áreas degradadas, como prescreve o art. 26 do Código Florestal (Lei No. 4.771, de 15 de setembro de 1965) (BRASIL, 1965), a Lei Federal No. 9.605 de 12 de fevereiro de 1998 (BRASIL, 1998), e o Decreto No. 3.179 de 21 de setembro de 1999 (BRASIL, 1999), submetendo os contraventores ao pertinente processo penal.

\section{CONSIDERAÇÕES FINAIS}

Os desastres naturais sempre fizeram parte da história da humanidade, inseridos no âmbito das (in)certezas e calcados na técnica e ciência na busca do controle sobre os eventos e domínio da natureza. O desastre natural resulta da combinação entre as características físicas do lugar, que refletem suas suscetibilidades e fragilidades associadas à capacidade de resposta e recuperação da sociedade expressas por sua vulnerabilidade e resiliência.

Os seres humanos estão sujeitos à exposição e ao convívio com os desastres naturais em diferentes graus de riscos. A história da relação entre os homens e destes com os modos de apropriação e uso dos recursos naturais mostra vínculos com os desastres naturais com relevantes impactos na sociedade. Assim, os desastres naturais são derivados da relação conflituosa entre sociedade/natureza e que podem agravar as mudanças climáticas na escala local.

A inserção dos desastres naturais no âmbito das (in)certezas que permeiam as mudanças climáticas tem sido uma constante em vários estudos sobre a temática.

A Revolução Industrial trouxe necessidades de reestruturações espaciais locais expressas pela urbanização crescente em nível mundial que estão atingindo elevados patamares no século $\mathrm{XXI}$, gerando os desastres naturais nas áreas consideradas de risco.

Em Cuiabá, a ocupação desordenada e a deficiência das políticas públicas de preservação da rede hídrica, de investimentos em saneamento e coleta de lixo provocam aumento significativo de inundações em bairros situados em áreas de risco. Estudos sobre o problema são 
necessários e urgentes, pois auxiliam a proposição e execução de ações preventivas em detrimentos das curativas, como as medidas para retirar e realocar, em definitivo, as pessoas que vivem em ocupações irregulares e de risco, pois em geral elas aceitam esta mudança enquanto estão em perigo e voltam quando cessa a turbulência.

As enchentes e inundações ocorridas em Cuiabá ocorrem em áreas de riscos que ficam localizadas às margens do rio Cuiabá. A situação dos córregos, da rede de drenagem e limpeza de boca de lobo dos bairros de Cuiabá que são atingidos pelas enchentes da época chuvosa necessita de cuidados e olhares diferenciados pelo poder público, pois é a população de menor poder aquisitivo que vive nestas localidades e convive com este grave problema durante a estação chuvosa.

Estes episódios de enchentes e/ou alagamentos obriga esta parcela da população a mudar do local de moradia, que na maioria das vezes, não ficam satisfeitas com a situação vivenciada e não raras vezes voltam à origem mesmo correndo perigo de enfrentamento de novos desastres naturais. Assim, a situação pós-desastres naturais, normalmente, é traumática e traz muitos episódios de intranquilidade para a população envolvida, Defesa Civil e os órgãos de planejamento da cidade.

É importante ressaltar a importância de proposições e execução de ações preventivas em detrimentos das curativas, como medidas para remanejamento, com justiça e respeito, destas pessoas que vivem em ocupações irregulares e em locais de riscos, pois em geral elas retornam às antigas habitações quando cessa a turbulência.

Enfim, para reduzir a suscetibilidade local e a vulnerabilidade da população são necessárias ações efetivas, sérias e comprometidas para a gestão sistemática dos riscos à desastres naturais que incluem as fases do salvamento e reconstrução, mas acima de tudo medidas de resiliência e respostas antecipadas aos desastres.

As ocorrências dos desastres naturais severos poderão se agravar ainda mais as mudanças climáticas na escala de abordagem local.

\section{AGRADECIMENTOS}

Este artigo deriva das investigações realizadas no âmbito do projeto Bolsa Produtividade em Pesquisa ( $\mathrm{PQ} 2$ ) concedida pelo CNPq à autora que expressa aqui seus agradecimentos.

\section{REFERÊNCIAS}

.A GAZETA. $\mathbf{8 0} \%$ dos córregos viraram esgoto e crescimento representa mais riscos. Artigo publicado em 5 de junho de 2009. Disponível em: <http://www.gazetadigital.com.br/pdf> Acesso em 27 set. 2010.

.ARAÚJO, E. C. R. Análise das Áreas de Preservação Permanente de Beira de Córregos e Rios do Perímetro Urbano da Cidade de Cuiabá-MT. Dissertação de Mestrado. UFMT. Departamento de Geografia/ Programa de Pós-Graduação em Geografia. 2010.

.CAMARGO, L.H.R. de A ruptura do meio ambiente - conhecendo as mudanças ambientais do planeta através de uma nova percepção da ciência: a geografia da complexidade. Rio de Janeiro: Bertrand Brasil, 2005. 237p

.CASTELLANO, M. S.; NUNES, L.H. Eventos climatológicos extremos na cidade de Campinas (SP) no período de 1991 a 2000. 12/2007, SIMPÓSIO BRASILEIRO DE DESASTRES NATURAIS E TECNOLÓGICOS, 2, v.1, 120. Santos, SP, 2007.

.CASTRO. P. R. $\mathbf{8 0 \%}$ dos córregos viraram esgoto e crescimento representa mais riscos. Artigo publicado em 5 de junho de 2009. Disponível em: <http://www.gazetadigital.com.br/pdf> Acesso em 27 set. 2010.

.DEFESA CIVIL DE CUIABÁ. Defesa Civil em Mato Grosso, 2009. Disponível em http://www.defesacivil.mt.gov.br Acesso em 10/08//2010.

EM-DAT The International Disaster Database. Disponível em: http://www.emdat.br/ acesso em 10/2/2009. 
.IPCC - Intergovernmental Panel on Climate Change. Climate Change 2004 e 2007: The Physical Science Basis. Summary for Policymakers. Disponível em: <http://w.ipcc.ch /SPM2feb07.pdf> Acesso em: 10/fevl/2007.

.ISDR - International Strategy for Disaster Reduction. Living with risk: a global review of disaster reduction initiatives. Preliminary version. Geneva, Switzerland: UN/ISDR, 2002.

.MATTEDI, M. A., e BUTZKE, I. C. A relação entre o social e o natural nas abordagens de hazards e desastres. Ambiente \& Sociedade, 9, 1-16. 2001

.MONTEIRO, C.A. de F. Clima e Excepcionalismo. Florianópolis: Editora UFSC. 1991.

.MONTEIRO, C.A. de F e MENDONÇA, F. Clima Urbano. Editora Contexto, 2003.

.NUNES, L.H. Mudanças climáticas globais. In: A.BORTOLOZZI, Debate ambiental: do conhecimento multidimensional à perspectiva de sustentabilidade. Campinas: NEPAN/UNICAMP, Cap. 1, 2002, p. 9-16.

.NUNES, L. H. Mudanças climáticas, extremos atmosféricos e padrões de risco a desastres hidrometeorológicos in População e Mudanças Climática - Dimensões Humanas das Mudanças Ambientais Globais. Campinas: Núcleo de Estudos de PopulaçãoNepo/Unicamp; Brasília: UNFPA, 2009, p. 53 a 73.

.ONU - Mudanças climáticas agravam riscos de desastres para os pobres (2009). Disponível pelo site http://ambientebrasil.com.br > Acesso em 23/09/2011.

.RODRIGUES, R.A; CASTRO S.S. A estrutura espacial das chuvas de Araguari (MG), durante a estação chuvosa 2001-2005. Ver. Geogr. Acadêmica vol. 2, n 1 (vi 2008) p. 43 - 45, 2000. Disponível pelo site: http://geograficaacademica.webng.com> Acesso 06 mai. 2010.SANTOS, Milton. Técnica, espaço, tempo: globalização e meio técnico-científicoinformacional. São Paulo, Hucitec, 1994.

.SANTOS, M. Metamorfose do Espaço Habitado. Hucitec.São Paulo 1988.

.SEDEC - Secretaria Nacional de Defesa Civil (SEDEC), Mato Grosso. 2010.

.SHIRASHI, F. K. Avaliação do efeito da construção do APM Manso no controle das cheias nas áreas urbanas da cidade de Cuiabá e Várzea Grande - MT. Tese, Universidade Federal do Rio de Janeiro/COOPE, Rio de Janeiro, 2003.

.TUCCI, C. E. M.; MARQUES, D. M. L. M. (org) Avaliação e controle da drenagem urbana. Porto Alegre: Editora da Universidade/UFRGS, 2000.UNDP - United Nations Development Programme (2004).

.VALENCIO, Norma; SIENA, Mariana; MARCHEZINI, Victor; GONÇALVES, Juliano Costa (orgs.). Sociologia dos desastres: construção, interfaces e perspectivas no Brasil. São Carlos: RiMa Editora, 2009. 280p. 